\title{
Differential requirement of bone morphogenetic protein receptors la (ALK3) and Ib (ALK6) in early embryonic patterning and neural crest development
}

\author{
Carolin Schille, Jens Heller and Alexandra Schambony ${ }^{*}$ (D)
}

\begin{abstract}
Background: Bone morphogenetic proteins regulate multiple processes in embryonic development, including early dorso-ventral patterning and neural crest development. BMPs activate heteromeric receptor complexes consisting of type I and type II receptor-serine/threonine kinases. BMP receptors la and Ib, also known as ALK3 and ALK6 respectively, are the most common type I receptors that likely mediate most BMP signaling events. Since early expression patterns and functions in Xenopus laevis development have not been described, we have addressed these questions in the present study.

Results: Here we have analyzed the temporal and spatial expression patterns of ALK3 and ALK6; we have also carried out loss-of-function studies to define the function of these receptors in early Xenopus development. We detected both redundant and non-redundant roles of ALK3 and ALK6 in dorso-ventral patterning. From late gastrula stages onwards, their expression patterns diverged, which correlated with a specific, non-redundant requirement of ALK6 in post-gastrula neural crest cells. ALK6 was essential for induction of neural crest cell fate and further development of the neural crest and its derivatives.

Conclusions: ALK3 and ALK6 both contribute to the gene regulatory network that regulates dorso-ventral patterning; they play partially overlapping and partially non-redundant roles in this process. ALK3 and ALK6 are independently required for the spatially restricted activation of BMP signaling and $m s \times 2$ upregulation at the neural plate border, whereas in post-gastrula development ALK6 exerts a highly specific, conserved function in neural crest development.
\end{abstract}

Keywords: BMP receptor, ALK3, ALK6, Xenopus, Dorso-ventral patterning, Neural crest

\section{Background}

Bone morphogenetic proteins (BMPs) are a subfamily of the TGF $\beta$ superfamily of secreted growth factors. Originally identified as regulators of bone formation [1-3] it is now well established that BMPs are major factors of dorso-ventral axis determination from Drosophila to mammals [4-10]. During later development, BMPs contribute to neural patterning and differentiation, the induction of the vertebrate neural crest and placodes and the development of the lens and inner ear [11-18].

\footnotetext{
* Correspondence: alexandra.schambony@fau.de

Biology Department, Developmental Biology, Friedrich-Alexander University Erlangen-Nuremberg, 91058 Erlangen, Germany
}

BMP signaling is also required in eye development, cardiac, kidney, and thymus organogenesis, germ cell differentiation, and hematopoiesis [19-25]. In addition, its roles in chondrogenesis, skeletal and limb development and patterning are well documented [reviewed in 26-29].

BMP ligands bind to and activate a tetrameric receptor complex composed of two type I and two type II receptors [30-34]. Type I receptors are also referred to as Activin-receptor Like Kinase (ALK). The human genome contains 35 Transforming Growth Factor beta (TGF $\beta$ ) family genes, but only seven genes encoding for type I, and five genes encoding for type II receptors. BMP receptors are single-pass transmembrane proteins and possess a serine/ 
threonine kinase domain in their intracellular domains [35-40]. BMP ligands activate only a subset of these receptors, namely BMP Receptor II (BMPRII) or Activin Receptor IIB (ActRIIB) as type II receptors and BMP Receptor Ia (BMPRIa/ALK3), BMP Receptor Ib (BMPRIb/ ALK6) or Activin Receptor Ia (ActRIa/ALK2) as type I receptors; in some cases, the Activin Receptor Ib (ActRIb/ ALK4) is also activated [41, 42]. Upon ligand binding the type II receptors phosphorylate and activate the type I receptors. In the canonical TGF $\beta$ signal transduction pathway, activated type I receptors phosphorylate a receptor substrate protein of the Mad/Smad family of transcriptional regulators (R-Smads). Phosphorylated Smads bind another Smad family member, the so-called Co-Smad, which itself is not a substrate of the type I receptor; they are then imported into the nucleus. Nuclear Smads associate with additional transcriptional regulators and cofactors, and regulate transcription of their target genes [reviewed in 43]. R-Smads are subdivided into two groups, the Smad $2 / 3$ and the Smad 1/5/8 groups, which mediate signaling by TGF $\beta$, Activin and Nodal ligands or by BMPs, respectively [reviewed in 44].

In Xenopus laevis, BMP4 is expressed in a semicircle at the ventral side of the embryo at early gastrula stage 10.5 and plays a major role in the induction of ventral cell fates $[7,45]$. Ventral BMP activity is antagonized by secreted BMP antagonists such as chordin or noggin that are derived from the organizer, thereby creating a BMP gradient that patterns the dorso-ventral axis [reviewed in 46]. Similar to ventral BMP4 expression in Xenopus, graded expression of BMP ligands is involved in dorso-ventral patterning in zebrafish [47]. BMP7, BMP2 and Anti Dorsalizing Morphogenetic Protein (ADMP) also contribute to ventral cell fate specification in Xenopus embryos, although these BMP ligands are expressed without dorso-ventral bias or even exclusively dorsal in the Spemann's organizer [6, 48-51]. In postgastrula embryos, BMP ligands are expressed in specific, spatially restricted patterns that reflect their role in the development of the respective tissues and organs. [6, 45, 48]. Similarly, in tadpole embryos expression of BMPR1a is found in the eye, otic vesicle, kidney, branchial arches, foregut and intersomitic tissue. BMPR1b expression is also detected in the head but not in trunk tissue [52-54].

By contrast, little is known about the expression patterns of BMP receptors in early Xenopus embryos. Here, we have analyzed the expression pattern and function of BMPRIa/ALK3 and BMPRIb/ALK6 in early Xenopus development. We observed only partial functional redundancy of the receptors in dorso-ventral patterning. In late-gastrula and neurula stages the expression patterns and function diverge markedly. In particular, we identified a specific, non-redundant function of ALK6 in neural crest development.

\section{Results and discussion}

\section{Expression of bmprla/alk3 and bmprlb/alk6 during Xenopus development}

We have cloned the full-length coding sequence of Xenopus laevis BMP-receptor Ia (BMPRIa/ALK3) and BMPreceptor Ib (BMPRIb/ALK6; see Additional file 1: Figure S1 for alignment of the ALK6 sequence and phylogenetic analysis, phylogeny data is also available at http://purl.org/ phylo/treebase/phylows/study/TB2:S18663). First, we compared their temporal and spatial expression pattern in early Xenopus embryos. In whole-mount in situ hybridization, alk3 RNA was detected in the animal hemisphere of early to late-blastula and early gastrula stage embryos. Its distribution expanded vegetally, but remained excluded from the vegetal pole, in mid-gastrula stage embryos (Fig. 1a). Notably, no dorso-ventral bias was observed. ALK6 RNA was not detected in blastula stages and only very weakly in early and mid-gastrula stage embryos. By late-gastrula, at Nieuwkoop and Faber stage 12 (NF stage 12, [55]) the spatial expression patterns of alk3 and alk6 became divergent. While alk3 expression remained ubiquitious, alk6 was specifically upregulated in the anterior neural plate. This temporal and spatial expression pattern is conserved between Xenopus and zebrafish gastrulae [56]. In the mouse, alk3 is also ubiquitously expressed until E9.5, whereas alk6 was detected only from E9.5 onwards and showed a more restricted expression pattern when compared to alk3 [57].

In neurula stages, alk3 was still ubiquitously expressed, but we observed a slightly more intense staining for alk3 at the neural plate border in NF stage 13 embryos and in the anterior neural plate in NF stage 16 embryos. Again, alk6 showed a strikingly different expression pattern during neurulation with the strongest expression at the neural plate border, in the anterior neural plate and in the prospective neural crest (Fig. 1a). The neural crest is induced at the neural plate border by a combination of intermediate levels of BMP signaling, WNT and FGF signaling [reviewed in 14, 58, 59]. Among the gene network that defines the neural crest, a subset of genes has been identified as direct targets of the BMP pathway via Smads, including the neural plate border specifying gene $m s \times 2$ [60] and slug [61]. Therefore the restricted expression pattern of ALK6 in the prospective neural crest suggests a specific role of alk6 in neural crest specification and development.

In early tadpole stages, expression of alk3 was detected in the brain and the eye, corresponding to the upregulation in the anterior neural plate at NF stage 16. By contrast, at NF stage 23, alk6 was strongly expressed in the brain, the ventral part of the eye and in the migrating neural crest cells (Fig. 1a). In later tadpole stages we observed expression of both genes in the brain, the eye, the otic vesicle and the branchial arches, alk3 transcripts were additionally detected in the heart, in intersomitic tissue and the pronephros (Additional file 2: Figure S2). 


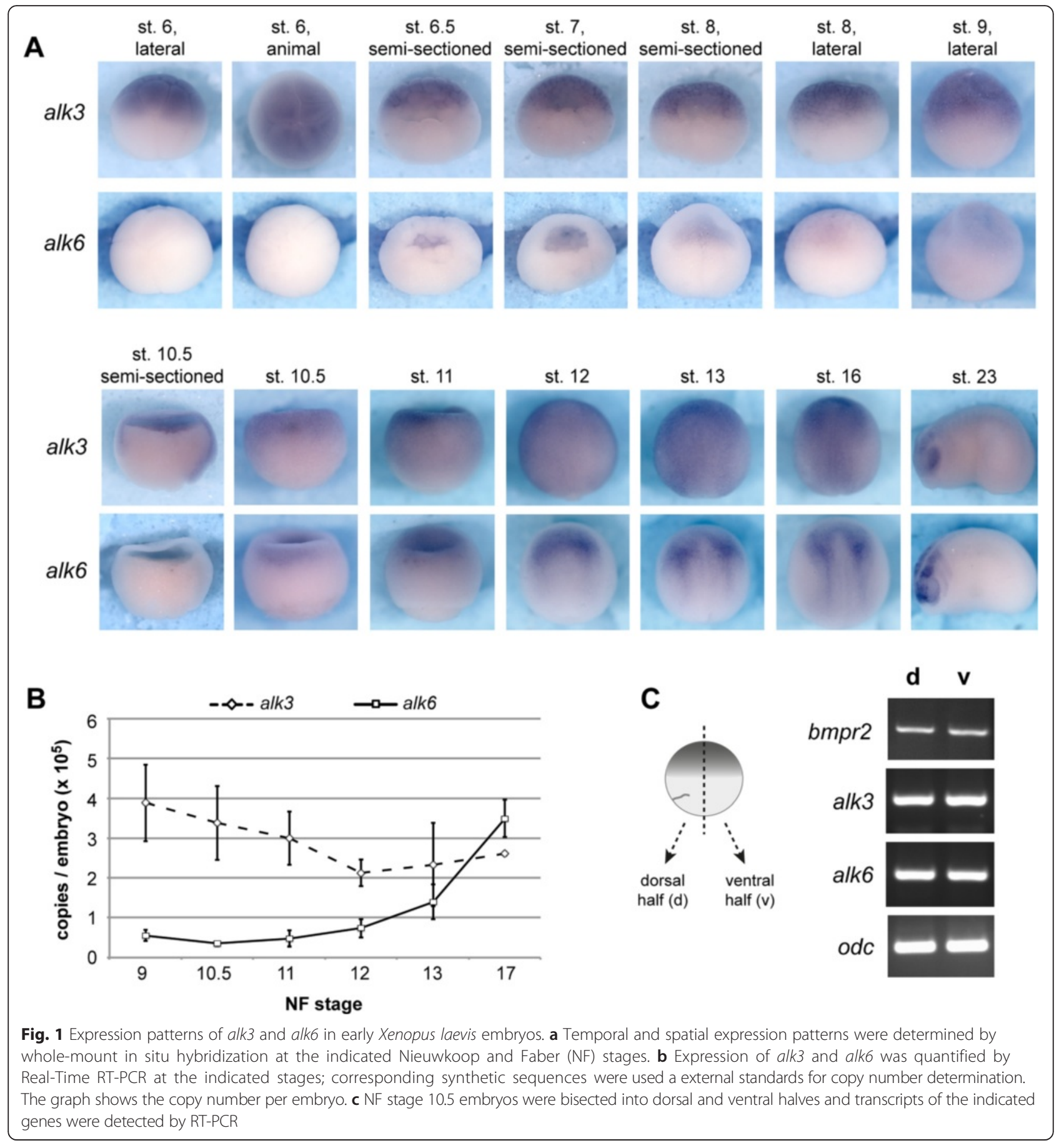

Alk6 was detected in the brain, eye, otic vesicle and branchial arches, although in a more spatially restricted pattern than alk3. In contrast to an earlier report [52], we also detected alk6 expression in the notochord (Additional file 2: Figure S2). These late expression patterns mostly recapitulate tadpole expression of both type I BMP receptors, as reported in other studies [52-54]. In addition, the tadpole expression showed considerable overlap with the expression of BMPRII [52, 62].
The increased expression of alk6 from late-gastrula onwards, which was detected by in situ hybridization (Fig. 1a), correlated well with the expression levels of alk3 and alk6 determined by Real-Time RT-PCR (Fig. 1b). Expression levels of alk3 decreased by $50 \%$ from NF stage 9 to NF stage 12 and then remained constant until stage 17. By contrast, alk6 levels were 6 to 10-fold lower than alk3 from NF stage 9 to 11 and showed a marked increase from NF stage 12 to 17, 
which resulted in an overall higher expression of alk6 when compared to alk3 at NF stage 17 (Fig. 1b). In addition, RT-PCR analysis of semi-sectioned NF stage 10.5 embryos confirmed that alk3, alk6 and also the type II receptor bmpr 2 were expressed equally in the dorsal and ventral halves (Fig. 1c). The same was true for the activin receptors acvr1a/alk2, acvr1b/alk4 and acvr2 at that stage (see Additional file 3: Figure S3).

The expression pattern of both alk3 and alk6 in preand early gastrula stage embryos mirrors the unbiased expression of BMPRII, BMP2 and BMP7 [6, 48, 62]. According to current knowledge, BMP2 and BMP7 and the ventrally expressed BMP4 activate ventralizing BMP signaling in early embryos. The dorso-ventral gradient of BMP activity found in late blastula and early gastrula Xenopus embryos [63] is shaped by ventrally expressed positive regulators and BMP antagonists arising from the dorsal organizer [reviewed in 46]. ALK3 and ALK6 can act as receptors for BMP2, BMP4 and BMP7 $[31,32,34,64]$; therefore, they are likely to mediate signaling from all three ligands in early embryos.

To further elucidate the role of ALK3 and ALK6 we have performed loss-of-function studies, focusing on pre-gastrula development and characterizing a putative specific role of ALK6 in the neural crest.

\section{Knock-down of ALK3 and ALK6 results in partially dorsalized embryos and additional specific phenotypes}

To investigate the role of ALK3 and ALK6 in Xenopus development, we have designed two translation-blocking antisense Morpholino oligonucleotides (MOs), which target non-overlapping sequences to knock-down each protein (see also Additional file 4: Figure S4).

We injected ALK3 MO or ALK6 MO into both blastomeres of two-cell stage embryos and analyzed the resulting phenotypes at NF stage 40. First, we noticed that knock-down of ALK6, particularly with ALK6 MO1, caused a higher lethality of embryos when compared to injection of ALK3 MO or control MO. At neurula stages, 63 of 147 embryos out of three independent injections with ALK6 MO1 survived whereas the numbers of surviving embryos injected with ALK6 MO2 (98/134), ALK3 MO1 (50/68) or ALK3 MO2 (97/122) were similar to the control MO (92/137). At stage 40, the survival of ALK6 MO1 and ALK6 MO2 injected embryos dropped to $17 \pm 13$ (total $28 / 147$ embryos) and $26 \pm 13 \%$ (total $42 / 134$ embryos) respectively. By comparison, 50-56 \% embryos survived to stage 40 after injection of either control MO, ALK3 MO1 or ALK3 MO2 (see also Additional file 5: Figure S5).

Compared to control embryos (Fig. 2a), we observed a range of phenotypes in the ALK3 or ALK6 morphant embryos that reached tadpole stage. The weakest phenotypes showed defects or partial loss of the ventral fin
(Fig. 2b) or defective pigmentation of the retina (Fig. 2c). Stronger phenotypes included anterio-dorsalized embryos with a progressive loss of ventral and posterior structures (Fig. 2d). A subset of embryos showed increased pigmentation of the head and less protruding branchial arches, indicating that neural crest development was affected (Fig. 2e). This phenotype was further investigated and the results are shown in Figs. 5 and 6. In addition, we observed complex phenotypes that affect multiple structures (Fig. 2f). Dorsalized and eye phenotypes were most frequent in ALK3 morphant embryos and no significant difference was observed between ALK3 MO1 and ALK3 MO2. By contrast, knock-down of ALK6 predominantly resulted in neural crest and pigmentation phenotypes. Although ALK6 MO2 appeared to induce the phenotype with higher frequency, the difference between ALK6 MO1 and ALK6 MO2 was statistically not significant (Fig. 2g).

Homozygous deletion of alk3 in mice is early embryonic lethal [65]. Because morpholino oligonucleotide injections in two-cell stage Хеnориs embryos did not deplete maternal protein, early lethality could not be expected. Homozygous alk6 knock-out mice are viable and show moderate skeletal phenotypes [66]. The same study suggested overlapping and redundant functions of ALK6 with other BMP receptors in mouse development. Since the knock-down of ALK6 in Xenopus embryos resulted in higher lethality and equally severe, albeit different phenotypes as compared to the ALK3 knock-down, less functional overlap of these two type 1 BMP receptors could be assumed in Xenopus laevis.

Compound phenotypes in the surviving embryos were expected, based on the complex expression patterns of alk3 and alk6, and are comparable to phenotypes reported for alk3 or alk6 loss-of-function in other vertebrates. The role of both, ALK3 and ALK6 in the development of the retina and lens is well established in mouse and chick embryos [67-69]. In addition, defects in brain and cranio-facial development as well as cartilage and bone formation have been described [66, 68-70]. Likewise, we observed defects in the forebrain region, smaller or absent eyes, which indicates that the developmental functions of ALK3 and ALK6 are conserved within vertebrates to a considerable extent. In addition, we observed aberrant pigmentation and cranio-facial deformation, indicating defects in the development of neural crest derived melanocytes and cartilage [71]. Interestingly and most notably, these phenotypes have been predominantly observed in ALK6 morphants, supporting a specific role of ALK6 in the development of the neural crest.

By contrast, we observed predominantly dorsalized phenotypes in ALK3-deficient embryos, which is in agreement with blastula-stage expression of ALK3 and its assumed role in early dorso-ventral patterning. Dorsalized 

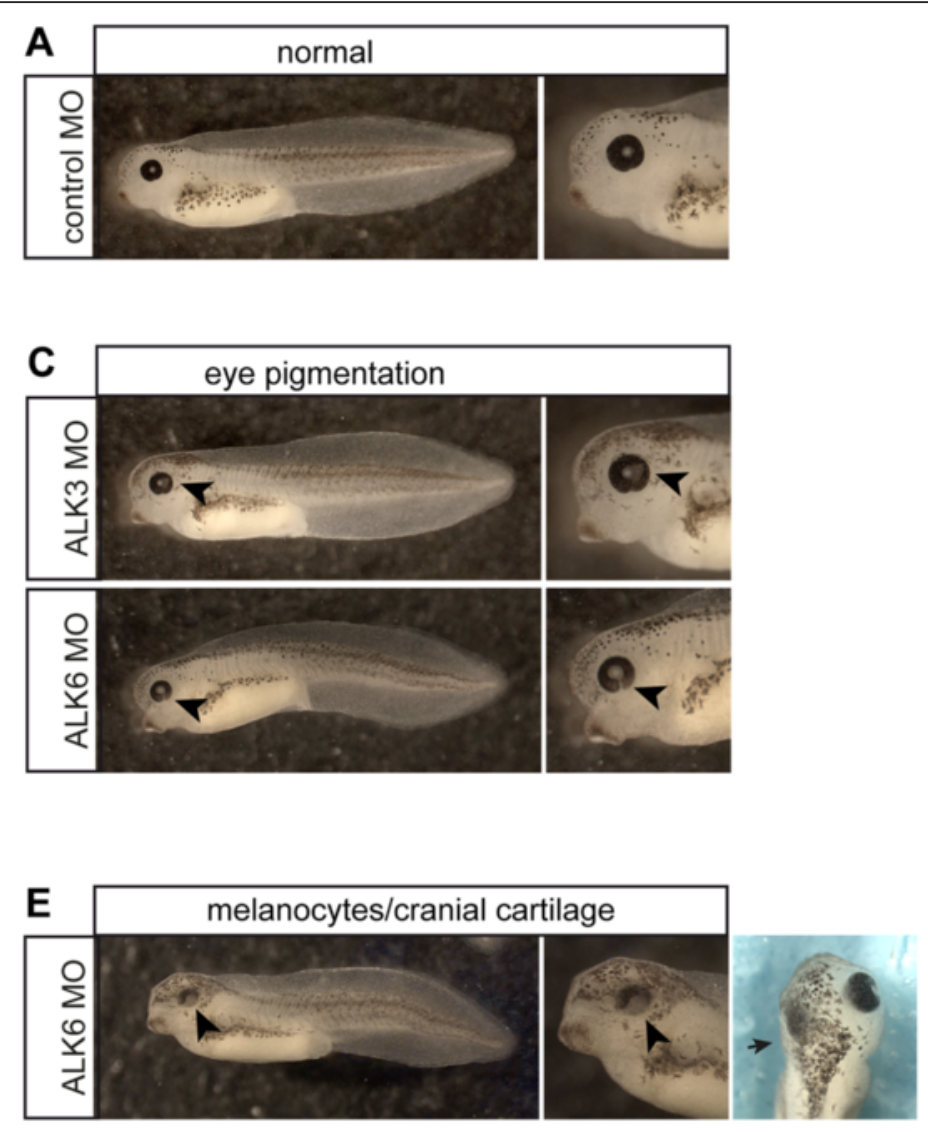

G
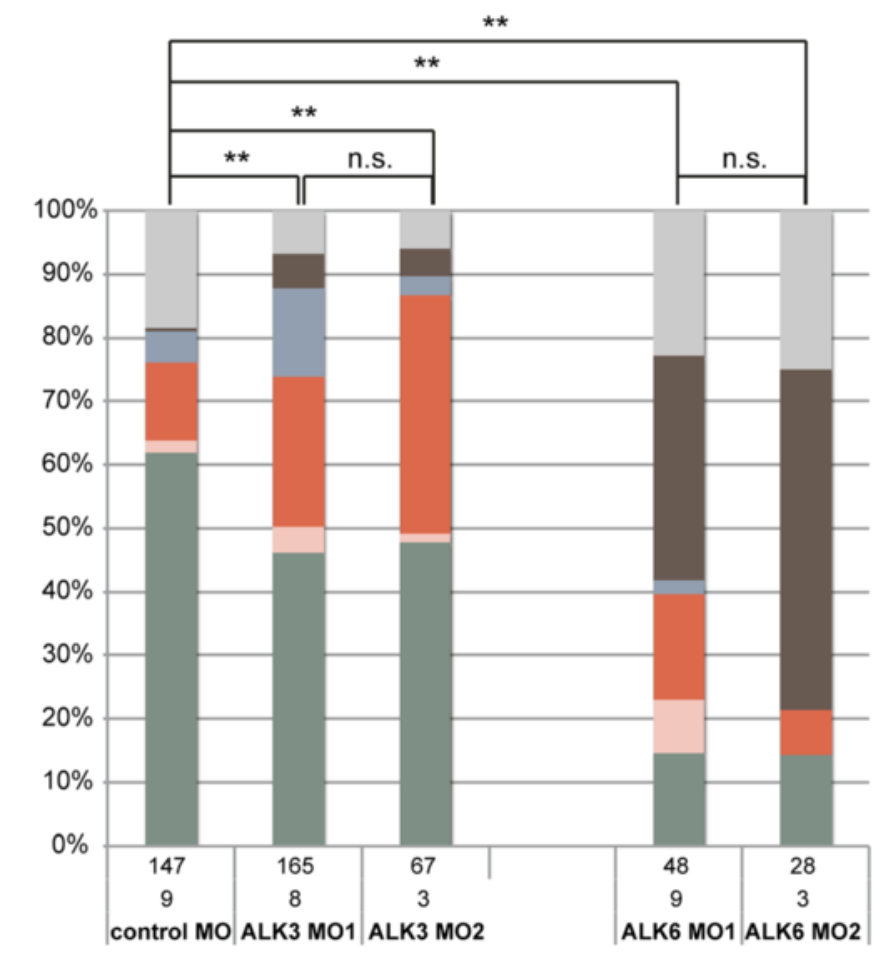
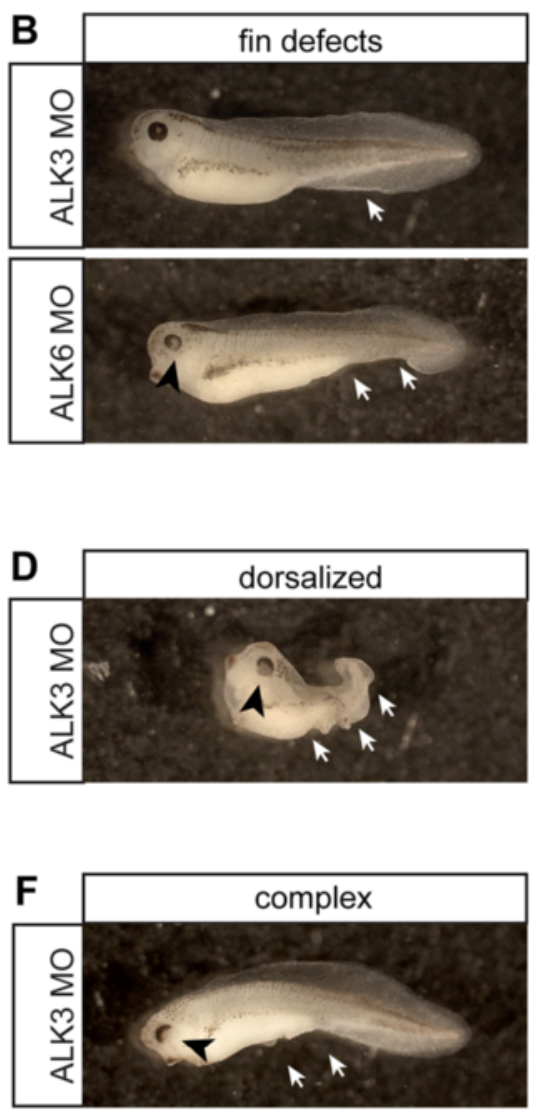

complex

- neural crest defect

= eye defect

" dorsalized

= fin defect

normal

Fig. 2 (See legend on next page.) 


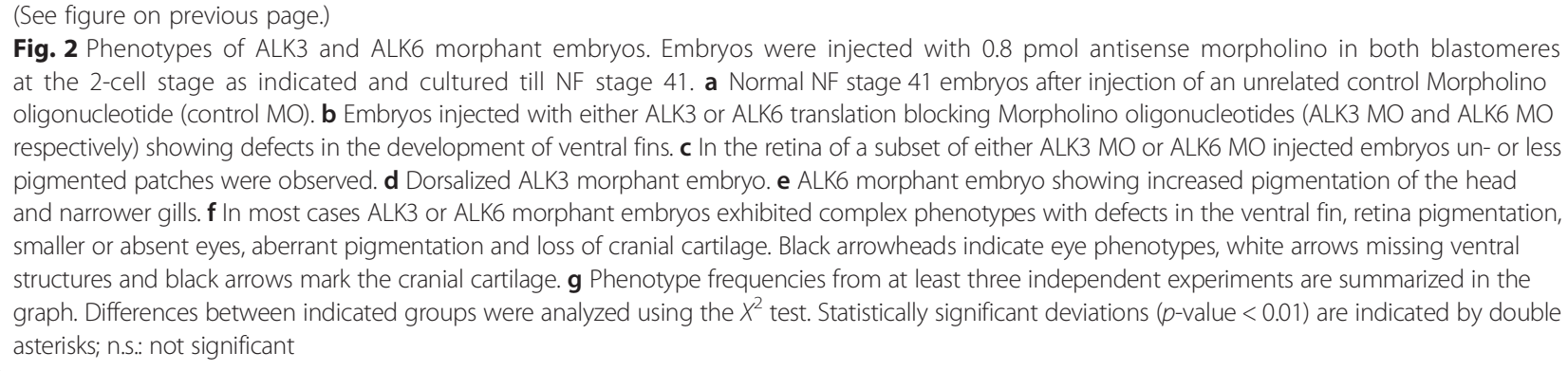

phenotypes were also observed in ALK6 morphant embryos although with lower frequency. The weakest phenotype affecting ventral structures were defects in the ventral fin, development of which depends on BMP signaling. In zebrafish, inactivating or dominantnegative mutations in BMP pathway genes, such as bmp $2 b$, smad5 or tolloid, result in the loss of the ventral fin [72, 73]. In Xenopus, formation of the ventral fin is similarly dependent on the ventral-most portion of the mesoderm [74] which is specified by BMP signaling. Interestingly, in zebrafish embryos, loss of the ventral fin has been attributed to ALK8, which is most closely related to ALK2 in other vertebrates $[75,76]$.

The higher frequency of dorsalized embryos in ALK3 morphant embryos, as compared to the ALK6 knockdown was consistent with the expression of these type I BMP receptors in pre-gastrula stage embryos. We already detected alk3 RNA in early blastula-stage embryos, whereas alk6 expression remained very low until late gastrula (NF stage 12, Fig. 1). Together these results support a major role of ALK3 and a minor contribution of ALK6 in transducing ventralizing BMP signals in early embryonic development.

\section{Both type I BMP receptors contribute to dorso-ventral patterning}

In order to confirm that the observed dorsalization phenotype in ALK3 and ALK6 morphant embryos was related to a role in early dorso-ventral axis specification, we next analyzed the influence of single and double knock-downs on the expression of the dorsally expressed organizer genes chordin, admp and goosecoid (gsc) $[49,77,78]$ as well as the ventral marker genes bmp4, vent 1 and sizzled $[7,79,80]$ in early gastrula stage embryos.

The transcripts of chordin, admp and goosecoid were exclusively detected in the dorsal halves of control embryos (Fig. 3a). In ALK3 morphants, these dorsal genes were also detected in the ventral halves of the embryos. This effect was weakest for chordin, but clearly detectable for admp and goosecoid. By contrast, in ALK6 morphant embryos the dorsal expression of admp and goosecoid appeared to be slightly weaker and no expression was detected in the ventral half. In the double morphant embryos, all three dorsal genes were clearly detected in the ventral hemisphere (Fig. 3a). The inverse was observed when we investigated expression levels of the ventrally expressed genes bmp4, vent1 and sizzled. Expression of bmp4 and vent 1 was lower in the ventral halves of ALK3, ALK6 or double morphant embryos. When analyzing sizzled expression a detectably weaker expression was only observed in double morphant embryos, whereas single knock-down of either ALK3 or ALK6 had no effect.

Although this experiment was not quantitative, it suggested that knock-down of ALK3 and double knockdown of ALK3 and ALK6 might result in an expansion of the organizer domain into the ventral half of the embryo, which would lead to a dorsalized phenotype. Dorsalization was indeed observed predominantly in ALK3 morphant embryos (see Fig. 2). Overall, these results indicated that both ALK3 and ALK6 play a role in dorso-ventral patterning and contribute to the expression of ventral genes, as demonstrated by the pronounced downregulation of bmp4, vent1 and sizzled in double morphant embryos.

In order to further investigate the effect of ALK3 or ALK6 depletion on the organizer, we performed whole mount in situ hybridizations using a chordin antisense probe in single-side injected embryos. Consistent with the aforementioned RT-PCR results, the area containing chordin-positive cells was enlarged by $50-70 \%$ in ALK3 morphant embryos injected with either ALK3 MO 1 or ALK3 MO 2, while the average staining intensity for chordin relative to the expression area remained unchanged (Fig. $3 \mathrm{~b}$ and c). This expansion of the chordinexpressing area was reverted by co-injection of alk3 RNA. By contrast, depletion of ALK6 did not significantly affect the distribution of chordin-expression or the relative staining intensity (Fig. $3 \mathrm{~b}$ and $\mathrm{c}$ ). Although ALK3 knock-down significantly expanded the chordinpositive area, this effect was mild when compared to the overexpression of a dominant-negative mutant of ALK3 (dnALK3/tBR, [81, 82]). DnALK3 induced strongly expanded and ectopic chordin expression in the majority of embryos (Fig. 3d). By contrast, we did not observe ectopic chordin expression in ALK3 morphant embryos. 

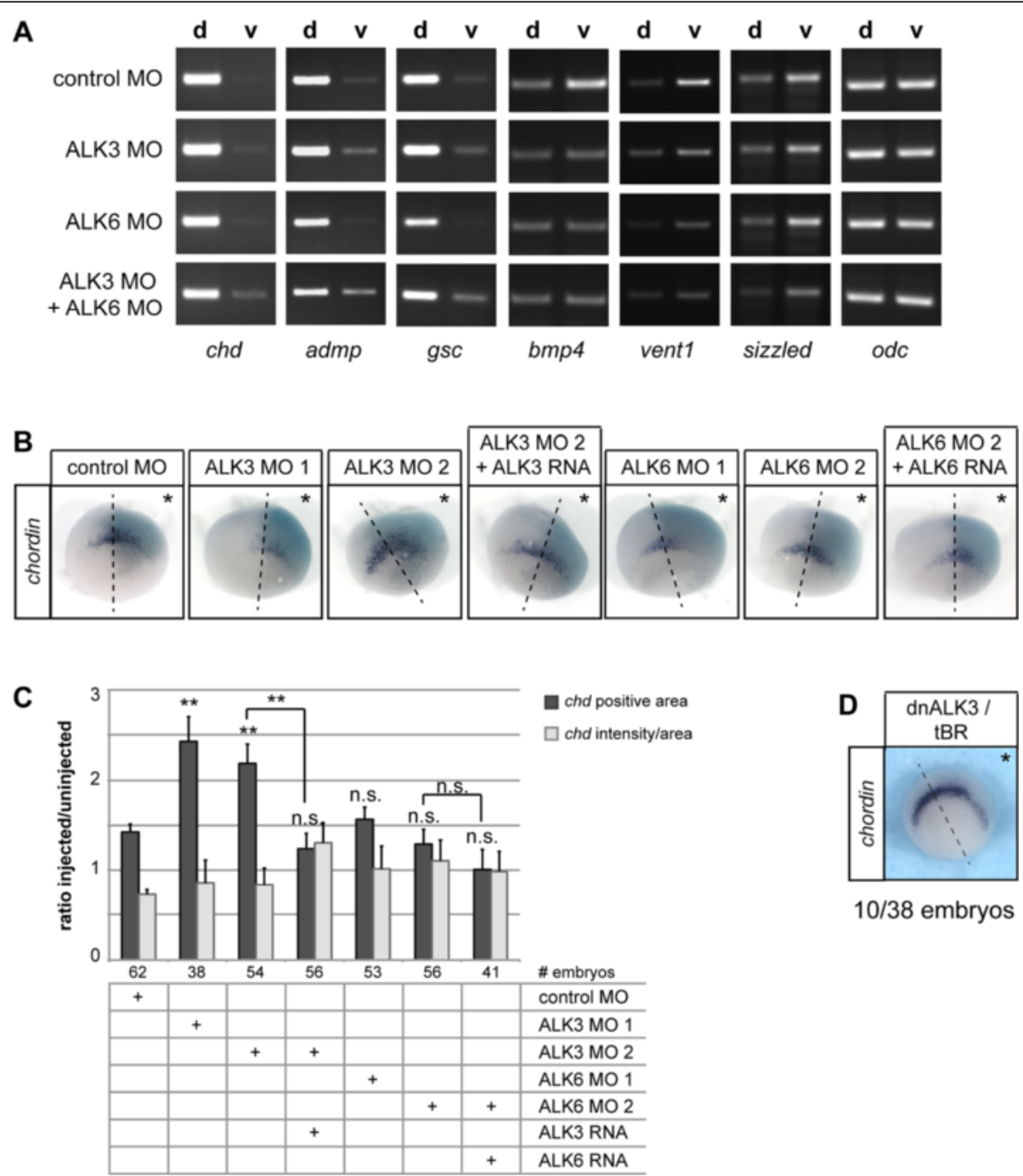

Fig. 3 ALK3 and ALK6 are required for dorso-ventral patterning. a 2-cell-stage embryos were injected with 1.6 pmol control MO, ALK3 MO or ALK6 MO in both blastomeres as indicated, cultured till stage 10.5 and bisected into dorsal (d) and ventral (v) halves. Expression of the organizer genes chordin (chd), admp and goosecoid (gsc) and the ventral genes bmp4, vent1 and sizzled was analyzed by RT-PCR. The images show one set out of three independent experiments. (b-g) Embryos were injected with Fluorescein-labeled dextran as lineage tracer and antisense Morpholino oligonucleotides as indicated into one blastomere at the 2-cell-stage. For rescue experiments, $50 \mathrm{pg}$ of alk3 RNA or alk6 RNA were co-injected. The embryos were cultured till stage 10.5 and chordin expression was visualized by whole-mount in situ hybridization. $\mathbf{b}$ Representative examples of phenotypes injected as indicated are shown. Asterisks indicate the injected side, dashed lines mark the dorsal midline as determined by the lineage tracer. c The chordin-positive area and staining intensity have been measured on the injected and uninjected side of each embryo. The graph displays the average ratio of area size between injected and uninjected side (+SEM) as well as the mean intensity/area (+SEM) from three independent experiments. Differences of area ratios between injection groups have been analyzed using a separate variance $t$-test and statistically significant deviations are indicated by double asterisks ( $p$-value $<0.01$ ); n.s.: not significant. The average intensity/area did not change significantly. d For comparison, an embryo injected with 50 pg RNA encoding dnALK3 is shown. In 10 out of 38 embryos dnALK3 induced strongly expanded or ectopic chordin expression

This discrepancy is likely due to the presence of maternal protein and possibly a contribution of additional type I receptors, such as ALK2 or ALK4 [41, 42] to the early BMP signal. Both ALK2 and ALK4 are expressed in early Xenopus embryos (see Additional file 3: Figure S3) and their activation by BMP ligands would also be inhibited by dnALK3 but not by ALK3 knock-down.
We next confirmed that the upregulation of dorsal genes in ALK3 morphant embryos observed at early gastrula stages indeed results in an expansion of dorsal tissues; therefore, we analyzed the influence of ALK3 knock-down on neural induction. Consistent with our previous results, single knock-down of ALK3 was sufficient to induce mild broadening of the neural plate and expression of the pan-neural marker sox 2 (Fig. 4a, b). 


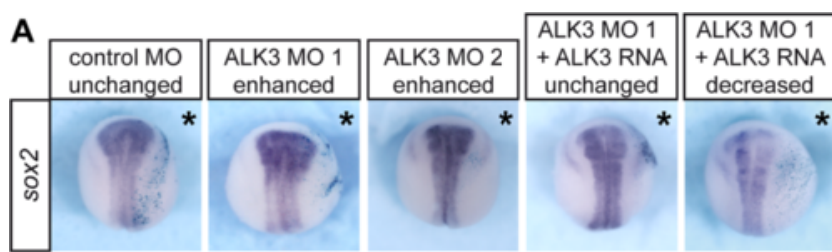

B
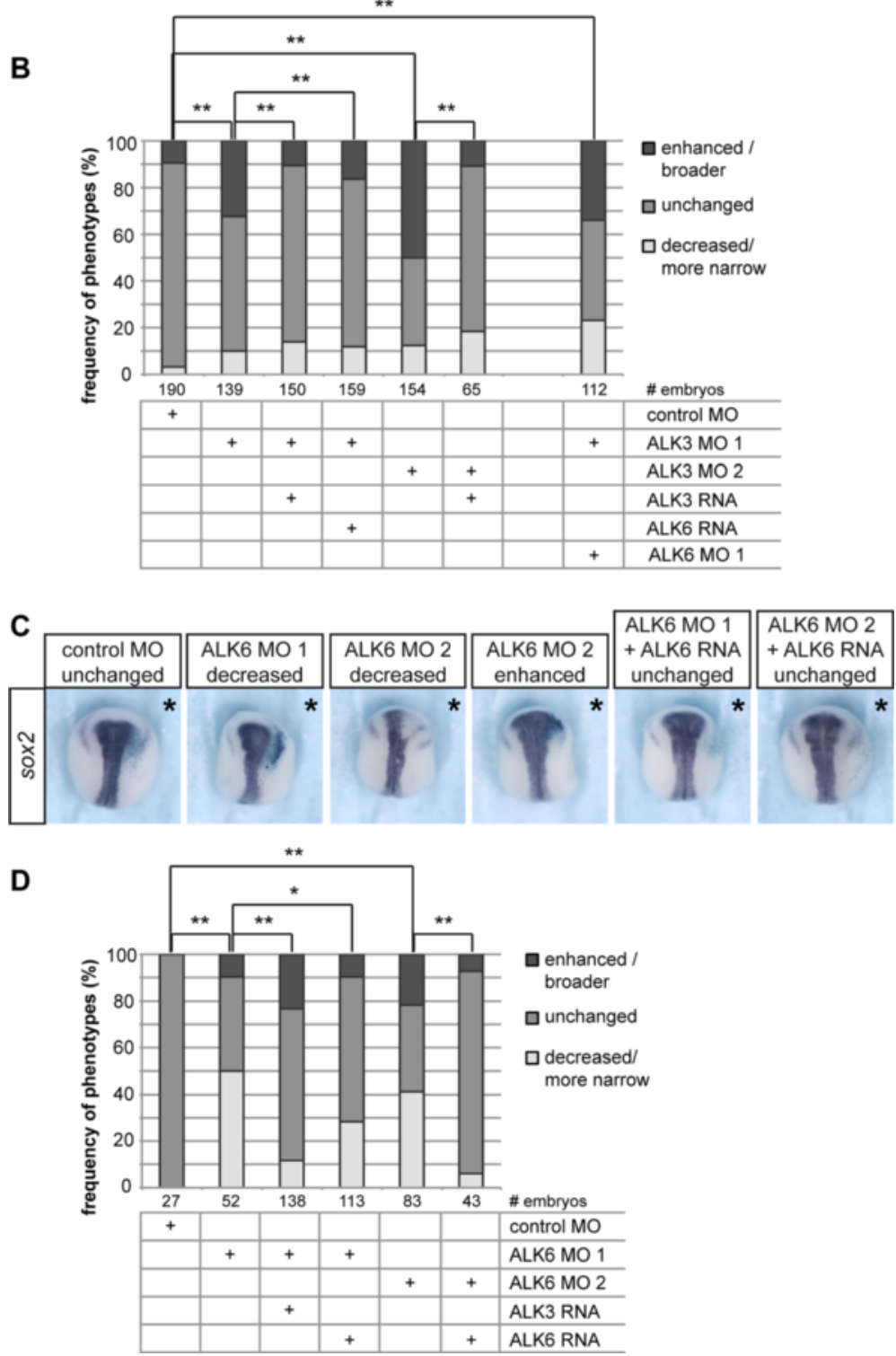

Fig. 4 Ectopic ALK6 can substitute ALK3 knock-down in dorso-ventral patterning. Embryos were injected laterally in one dorsal blastomere at the 4-cell stage with $0.8 \mathrm{pg}$ of ALK3 or ALK6 MOs and, for rescue experiments, co-injected with $50 \mathrm{pg}$ of alk3 RNA or alk6 RNA. A lacZ plasmid was co-injected to identify the injected side, embryos were cultured till stage 18 and stained for LacZ. The neuroectoderm was visualized by in situ hybridization against the pan-neural marker gene sox2. Embryos were categorized according to expanded or reduced sox2 expression and differences between indicated groups were analyzed using the $X^{2}$ test. Statistically significant deviations $(p$-value $<0.01)$ are indicated by double asterisks; n.s.: not significant. a Representative images of ALK3 morphant embryos and the corresponding rescue experiments are shown. Embryos were injected as indicated; asterisks indicate the injected side. $\mathbf{b}$ Results from at least three independent experiments are summarized in the graph. c Representative images of ALK6 morphant embryos and the corresponding rescue experiments are shown. Embryos were injected as indicated; asterisks indicate the injected side. $\mathbf{d}$ Results from at least three independent experiments are summarized in the graph 
This ALK3 MO 1 phenotype was rescued by coinjection of either morpholino-insensitve ALK3 RNA or ALK6 RNA, demonstrating the specificity of this knockdown phenotype and functional redundancy of ALK3 and ALK6 (see also Additional file 7: Figure S7). Bringing back ALK3 also resulted in a downregulation of sox2 in roughly $15 \%$ of the embryos, which indicated an over-compensation of the morphant phenotype. Comparable results were obtained using ALK3 MO 2; the size of the sox2-positive area was increased by $12.5 \pm$ $2.6 \%$ by injection of ALK3 MO 1 and by $11 \pm 3.1 \%$ by ALK3 MO 2 respectively. However, in embryos injected with ALK3 MO 2, broadening of the neural plate occurred more frequently as compared to ALK3 MO 1 (Fig. 4a, b). Double knock-down of ALK3 and ALK6 did not further increase the percentage of embryos showing an enlarged sox2-positive area.

We repeated this experiment and targeted the injections to one animal blastomere of eight-cell stage embryos, which should limit the knock-down to the ectoderm and avoid interfering with organizer formation. The outcome was very similar to the results obtained after injection at the four-cell stage (Additional file 6: Figure S6). Ectodermal knock-down of ALK3 by ALK3 MO 1 or ALK3 MO 2 resulted in an increase of the sox2-positive area by $14 \pm 3.1$ and $18 \pm 6.9 \%$ respectively. Again, the phenotype was rescued by both alk3 RNA and alk6 RNA. These results indicated that in addition to its role in early dorso-ventral specification, ALK3 also influenced ectodermal patterning.

Overall, we have demonstrated a role for ALK3 in the specification of ventral cells fates and ectodermal patterning. However, we observed only moderate dorsalization even after ALK3/6 double knock-down. Our data are consistent with a comparable study in zebrafish in which the double knock-down of ALK3 and ALK6 resulted in only weakly dorsalized phenotypes [56]. Morpholino mediated knock-down did not affect maternal protein, which is possibly a cause for these results. In addition, triple knock-down of the BMP ligands BMP2, BMP4 and BMP7 induced only moderate dorsalization with decreased sizzled expression and no effect on chordin [50]. The same group showed that strong dorsalization required additional knock-down of ADMP [51]. Knock-down of ALK3 or ALK6 is not expected to affect ADMP activity, because ADMP does not bind to ALK3 or ALK6, but to ALK2 [51]. ALK3 and ALK6 have been identified as receptors for BMP2, BMP4 and BMP7 in multiple studies $[34,64,83]$. Both ALK3 and ALK6 form receptor complexes with BMPRII $[31,36]$ and BMP2 as well as BMP7 signal via heteromeric receptor complexes comprising different type I receptors in dorsoventral patterning in zebrafish [84]. Therefore the highly similar effect of BMP2/4/7 knock-down [50] and
ALK3/6 knockdown (this study) support the conclusion that ALK3 and ALK6 predominantly act as receptors for BMP2, BMP4 and BMP7 ligands in early dorsoventral patterning.

Moreover, we observed that ALK3 knock-down is sufficient to expand the expression territory of organizer genes in early gastrula stage embryos, indicating that ALK3 is the dominant type I receptor in the BMP activity gradient that antagonizes expression of organizer genes. Such a bigger role for ALK3 as compared to ALK6 is in agreement with higher expression levels of ALK3 in pre- and early gastrula stages.

We also analyzed sox2 expression in ALK6 morphant embryos. Interestingly, injection of ALK6 MO 1 or ALK6 MO 2 into one dorsal blastomere of four-cell stage embryos resulted in an anterior downregulation of sox 2 on the injected side at neurula stages (Fig. 4c and d). The size of the sox2-positive area was reduced by 10 \pm 2.1 and $17 \pm 3.1 \%$ in embryos injected with ALK6 MO 1 and ALK6 MO 2, respectively. This phenotype was rescued by co-injection of either alk3 RNA or alk6 RNA (see also Additional file 7: Figure S7), which is contradictory to the results shown above that demonstrate a role of ALK3 in ventral specification and antagonizing neural induction. An ALK3 gain-of-function would be expected to inhibit neural induction and thus reduce the size of the sox 2 expression area. In addition, these results overall are contradictory to the theory that BMP activity antagonizes neural induction [6]. Moreover, we did not observe a significant effect of ALK6 knock-down on the size of the organizer as determined by the chordin-positive area at early gastrula (Fig. $3 \mathrm{~b}$ and c). Taking into account that alk6 expression is very low during gastrulation but upregulated in the anterior neural plate and neural plate border at late gastrula and early neurula stages, this decrease of sox2 is possibly not caused by alterations of the early BMP gradient. Instead, a role of ALK6 in the development or maintenance of anterior neural tissue after neural induction might be hypothesized, however, the nature and mechanism of such a putative function remains to be investigated.

\section{ALK6 is required for neural crest specification}

The ALK6 morphant phenotype with embryos showing a marked increase of pigment cells, and in some cases a dramatic loss of cranial cartilage, indicated defects in neural crest development (see Fig. 2). Since ALK6 is specifically upregulated in the neural crest during neurulation (Fig. 1a), we analyzed its role in neural crest development in more detail.

ALK6 morphant embryos frequently showed an increased number of melanocytes in the dorsal head region, which was in most cases accompanied by deformed branchial arches (Fig. 1). Closer examination of these embryos 
A
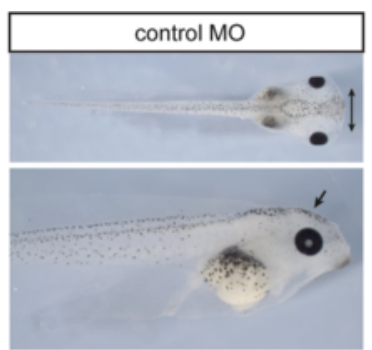

B

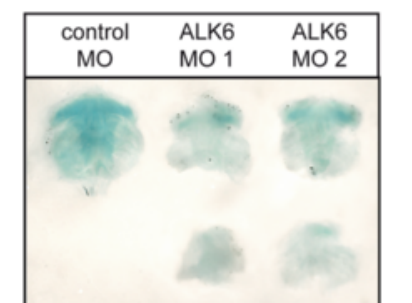

B'
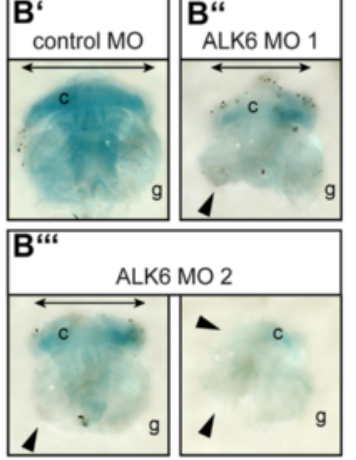

E

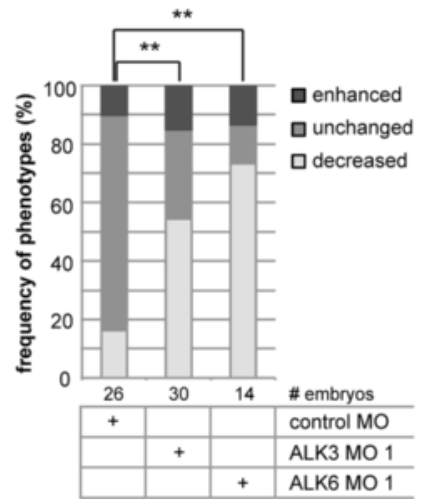

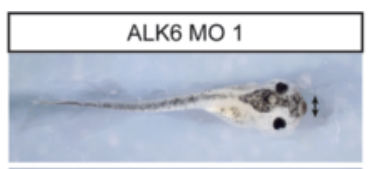
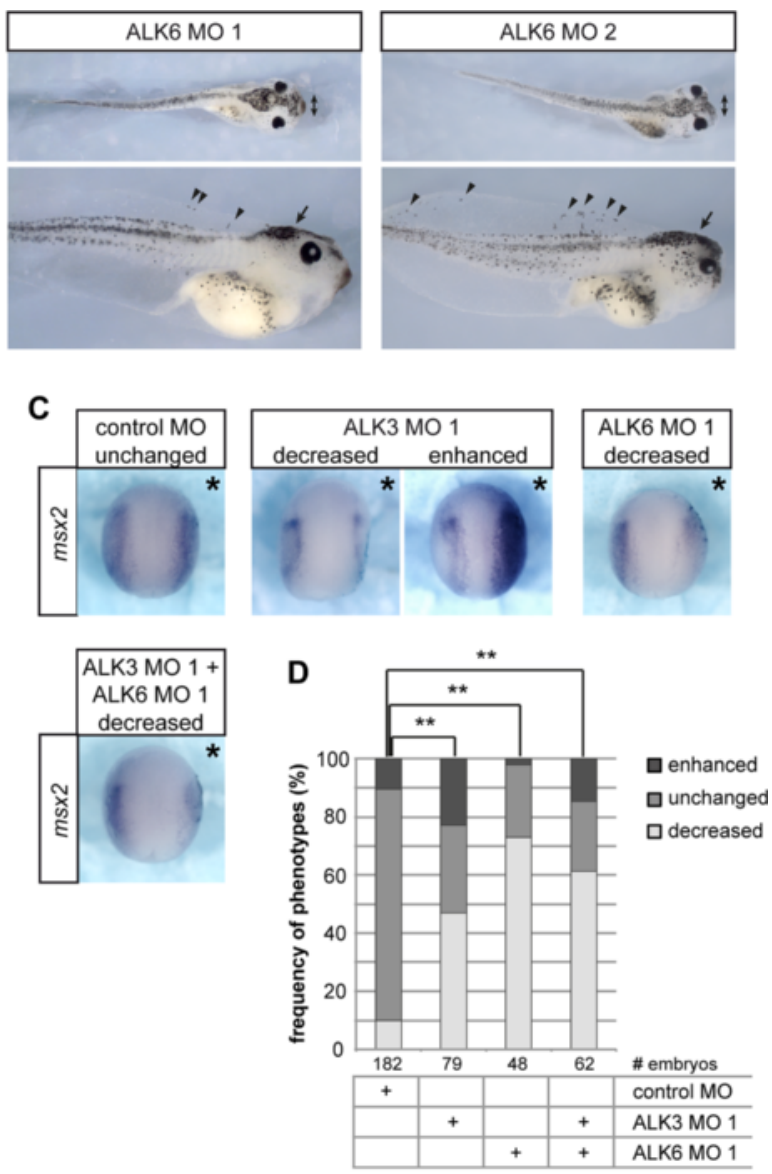

F

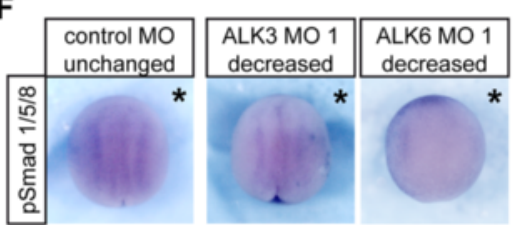

Fig. 5 ALK6 is required for neural crest development. a When compared to control MO injected embryos, ALK6 morphant embryos showed increased pigmentation of the head (arrow), ectopic melanocytes in the dorsal fin (arrowheads) and narrower heads reflected by less lateral protrusion of the gills and smaller distance between the eyes (double arrow). b Cranial cartilage from embryos injected as indicated was stained with Alcian Blue dye. Cartilage from ALK6 morphant embryos generally showed weaker staining, was smaller (double arrows in B', B" and B"') and showed partial or complete loss of cartilage elements (arrowheads in $\mathrm{B}^{\prime}, \mathrm{B}^{\prime \prime}$ and $\mathrm{B}^{\prime \prime \prime}$ ) of the gills $(\mathrm{g})$ or ceratohyal cartilage $(\mathrm{c})$. The images in A and B show representative examples from one out of three independent experiments. $\mathbf{c}$ Embryos were injected with 1.6 pmol morpholino in one animal-dorsal blastomere at the 8-cell stage as indicated. A lacZ plasmid was co-injected to identify the injected side, embryos were cultured till stage 13 and stained for LacZ. Expression of msx2 was analyzed by whole-mount in situ hybridization. Representative images of embryos injected as indicated are shown. Asterisks indicate the injected side. The results from three independent experiments are summarized in the graph (d). Active BMP signaling at the neural plate border was shown by whole-mount immunostaining for phosphorylated Smad 1/5/8 (pSmad 1/5/8). e The graph shows a summary of pSmad1/5/8 staining results from two independent experiments. In (f) representative images of embryos injected with control MO, ALK3 MO 1 or ALK6 MO 1 are shown. Embryos were categorized according to decreased or enhanced $m s \times 2$ expression or pSmad 1/5/8 staining respectively and differences between indicated groups were analyzed using the $X^{2}$ test. Statistically significant deviations $(p$-value $<0.01)$ are indicated by double asterisks; n.s.: not significant 
revealed aberrant localization of melanocytes in both ALK6 MO 1 and ALK6 MO 2 injected embryos. Many melanocytes were found in the dorsal head region, whereas the flank in most embryos was less pigmented. In addition, we observed ectopic melanocytes in the dorsal fin (Fig. 5a), indicating aberrant specification or migration of neural crest derived melanocyte precursors.

Embryos showing aberrant pigmentation were subjected to Alcian Blue staining of the cranial cartilage. All ALK6 morphant embryos showed fainter cartilage staining, indicating incomplete cartilage differentiation. In addition, we observed a range of defects in the cranial cartilage. In milder cases, parts of the gills were missing and the ceratohyal cartilage was smaller or deformed; overall, the cartilage elements present were only faintly stained. In the most severe cases, only tiny, unstructured remnants of cartilage were found (Fig. 5b). The requirement of ALK6 in chondrogenic differentiation of the cranial cartilage, as indicated by reduced Alcian Blue staining, is consistent with the role of ALK6 in cartilage and bone formation in the mouse $[66,85]$. Moreover, the partial or complete loss of cranial cartilage elements (Fig. 5b) together with the prominent expression of alk6 in pre-migratory and migrating neural crest cells (Fig. 1a) indicated an additional role in early neural crest development.

Neural crest development begins in the dorso-lateral marginal zone of early gastrula embryos in Xenopus. In this region attenuated BMP activity combined with active Wnt/ $/$-Catenin signaling specifies neural crest precursors $[14,86]$. After gastrulation neural crest precursors are located at the neural plate border and identified by the expression of a specific set of transcription factors, including $m s \times 1$ and $m s x 2$, that induce further neural crest development [59, reviewed in 87].

To address the question of whether the neural crest is not induced in ALK6 morphants or if neural crest cells get lost during pre-migratory development, we analyzed the expression of $m s x 2$ in the neural plate border at late gastrula stages. Both ALK3 and ALK6 loss-of-function resulted in a downregulation of $m s x 2$, although $23 \%$ of ALK3 morphant embryos showed an increase of $m s x 2$ (Fig. $5 \mathrm{c}$ and d). In the ALK6 morphants, no increased $m s x 2$ expression was observed, but more than $70 \%$ of embryos showed a decrease or loss of $m s x 2$ expression (Fig. 5d), thus demonstrating further that particularly ALK6 plays a crucial role in neural crest development. Interestingly, the frequency of increased and decreased msx 2 expression in double morphant embryos represented the average of phenotype frequencies that were observed in the single knock-downs (Fig. 5d), indicating that ALK3 and ALK6 affect $m s x 2$ expression independently of each other.
It has been shown that reducing BMP activity in blastula or gastrula stages results in a shift and expansion of the neural plate border area as well as upregulation of neural crest markers [88]. Such expansion of the $m s x 2$ expression area was only observed in approximately one quarter of ALK3 morphant embryos, which is consistent with the role of ALK3 in dorso-ventral patterning discussed above. On the other hand, $m s \times 1$ and $m s x 2$ are regulated by BMP signaling, and $m s x 2$ has been identified as a direct BMP target $[13,60,89]$. The observed downregulation of $m s x 2$ in ALK3 and ALK6 morphant embryos coincided with the upregulation of both type I receptors at the neural plate border in late gastrulation (see Fig. 1a); together, these observations strongly suggested a role for ALK3 and ALK6 in this Smad-dependent transcriptional regulation.

To confirm that both receptors signal to Smad at the neural plate border, we probed NF stage 13 embryos for the presence of active phosphorylated Smad1/5/8 (pSmad1/5/8) using a phospho-specific antibody. We observed a narrow stripe of $\mathrm{pSmad} 1 / 5 / 8$ positive cells along the neural plate border. This local activation of BMP signaling was detectable from NF stage 12.5 onward, again coinciding with the upregulation of ALK6 as well as ALK3, albeit to a lesser extent, at the neural plate border. After injection of ALK3 MO, we detected a decrease of pSmad 1/5/8 at the neural plate border in approximately $50 \%$ of the embryos. The effect was again more pronounced in ALK6 morphants (Fig. 5e and f), which showed a reduction of pSmad $1 / 5 / 8$ in over $70 \%$ of the embryos. This result demonstrated that both ALK3 and ALK6 activate Smad in neural plate border cells. Moreover, pSmad data were highly similar to the $m s x 2$ expression data (Fig. $5 \mathrm{~d}$ and $\mathrm{f}$ ), which is consistent with $m s \times 2$ being a direct target gene of BMP signaling [60]. Therefore it is conceivable that both ALK3 and ALK6 contribute to the activation of Smad at the neural plate border, thereby upregulating BMP-responsive neural plate border genes such as $m s x 1$ and $m s x 2$. According to current models of neural crest development in Xenopus, neural crest precursors are first specified at early gastrula stages by the combined input of low BMP and low Wnt/ $\beta$-Catenin signaling $[14,90]$. During gastrulation, cells located lateral of the future neural plate receive $\mathrm{Wnt} / \beta$-Catenin, FGF, Notch and BMP signals that induce the expression of neural plate border specifying or pre-patterning genes such as $g b x 2, p a x 3, z i c 1, m s x 1$ and the BMP target gene $m s x 2$ [13, 58-60, 87, 91-93]. These neural plate border factors govern further induction of neural crest cells and the expression of genes required for proliferation, survival and migration of the neural crest, including ap $2 \alpha$, foxd3, sox8, sox9, sox10, slug, snail and twist [58, reviewed in: 59, 87, 94-99]. 

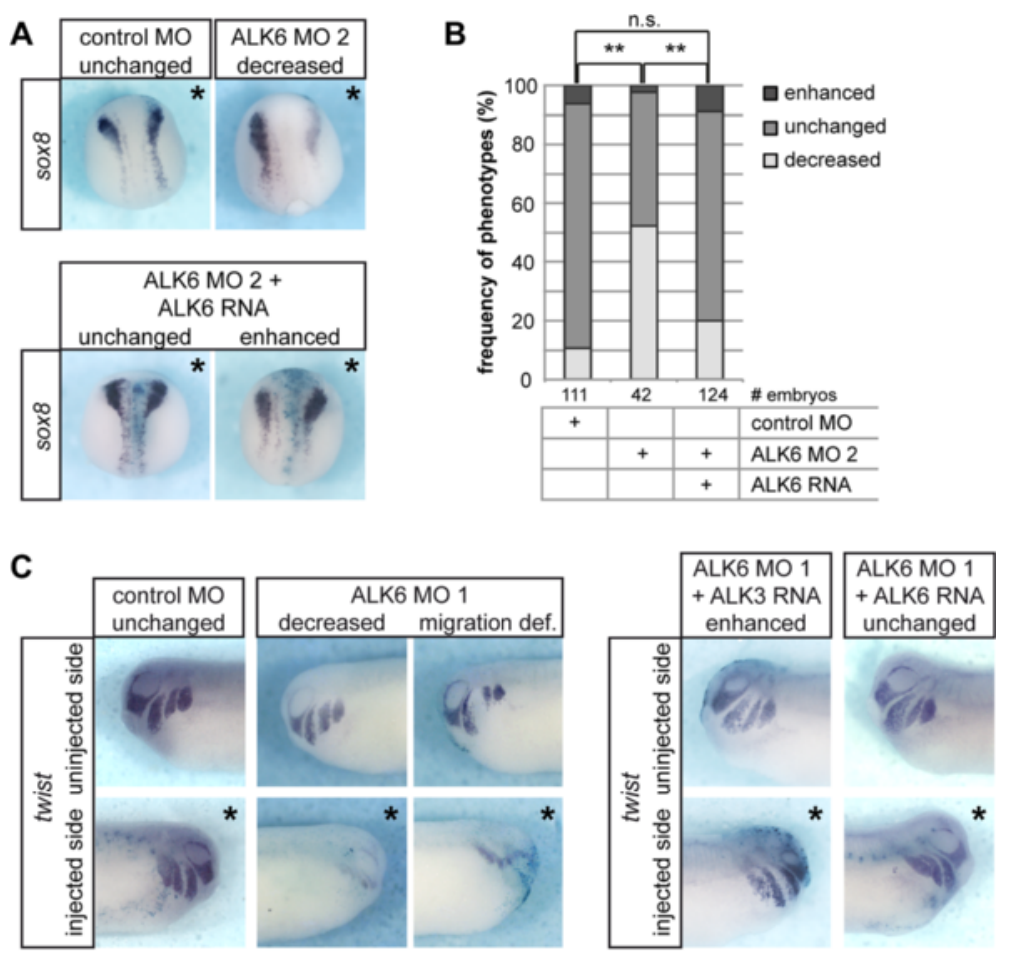

D

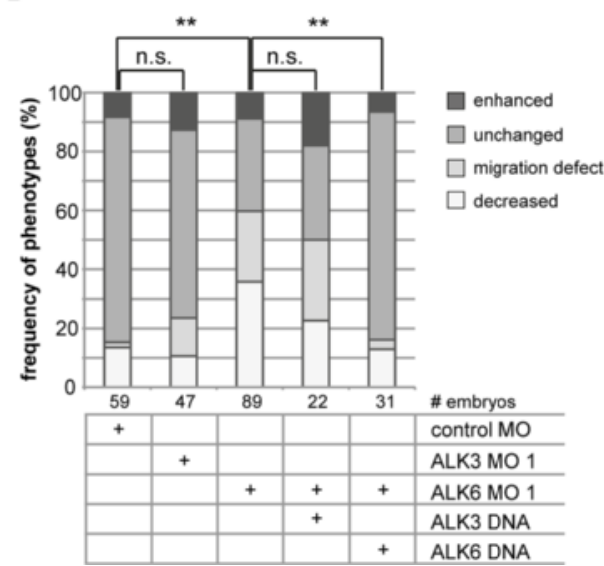

Fig. 6 Analysis of sox8 and twist expression in ALK6 morphant embryos. Embryos were injected with 1.6 pmol morpholino targeted animally in one dorsal blastomere at the 4-cell stage. A lacZ plasmid was co-injected to identify the injected side, embryos were cultured till stage 18 or 24 and stained for LacZ. The neural crest was visualized by in situ hybridization against sox 8 at stage 18 and against twist at stage 24 . Differences between indicated groups were analyzed using the $X^{2}$ test. Statistically significant deviations $(p$-value $<0.01)$ are indicated by double asterisks; n.s.: not significant. a Representative images of embryos hybridized against sox8 and injected as indicated are shown. The ALK6 MO phenotype was rescued by co-injection of $50 \mathrm{pg}$ alk6 RNA. Asterisks indicate the injected side. The results from three independent experiments are summarized in the graph (b). c Representative images of the uninjected and injected sides of embryos of stage 24 embryos hybridized against twist are shown. Embryos were injected with 1.6 pmol of ALK6 MO 1; for rescue experiments 25 pg of alk3 plasmid DNA or alk6 plasmid DNA were co-injected. The results from three independent experiments are summarized in the graph (d)

Consistent with a role of ALK6 in neural plate border specification, sox8 was severely downregulated in ALK6 depleted embryos at neurula stages (Fig. $6 a$ and b). We observed decreased expression of sox8 in approximately $50 \%$ of all embryos injected with ALK6 MO2. Coinjection of MO-insensitive alk6 RNA fully rescued sox8 expression and further supported a role of ALK6 in neural crest induction (Fig. 6a and b). Interestingly, the frequency of the neural crest induction phenotype dropped from over $70 \%$ of embryos showing decreased $m s x 2$ expression at NF stage 13 to $50 \%$ embryos with decreased sox8 expression at NF stage 18. This decline of phenotype frequency indicated a partial regeneration of neural crest cells; such regenerative potential has also been observed in chick 
embryos after removal of neural crest cells [100]. In addition, proliferation of pre-migratory neural crest cells could contribute to the observed partial recovery of the neural crest population between NF stage 13 and NF stage 18.

We next visualized the migrating neural crest in NF stage 26 embryos by in situ hybridization for twist expression. ALK6 MO 1 injection induced a downregulation of twist in $36 \%$ of the embryos (Fig. $6 \mathrm{c}$ and d). This further decline in frequency of the "decreased" neural crest marker gene phenotype supports the assumption that the neural crest population is partially recovering in ALK6 morphant embryos. By contrast, single knockdown of ALK3 resulted in less than $15 \%$ of induction defects (Fig. 6d) as compared to $45 \%$ at NF stage 13 (Fig. 5d). This might simply indicate a delayed specification of the neural plate border in ALK3 depleted embryos, where ALK3 function could be compensated albeit belatedly by redundant proteins, such as ALK6, during later neural crest development. Notably, ALK6 knock-down was not fully compensated until tadpole stages, which suggests a partially non-redundant role of ALK6 in post-induction neural crest development. Such an additional role of ALK6 is further supported by the occurrence of impaired neural crest migration in $24 \%$ of ALK6 morphant embryos that was not observed in ALK3 MO-injected embryos (Fig. 6c and d). However, it cannot be concluded whether ALK6 itself plays a direct role in neural crest migration or if the observed migration defects are secondary effects of impaired neural crest specification in these embryos.

To rescue the ALK6 MO phenotype without interfering with dorso-ventral patterning, we co-injected plasmids encoding ALK3 or ALK6 that are expressed only when zygotic transcription is initiated after the mid-blastula transition. The neural crest phenotype in ALK6 morphants was not rescued by co-injection of alk3 plasmid DNA, although an upregulation of twist was observed in a low percentage of embryos when ALK3 was overexpressed in the ALK6 morphant background (Fig. 6c and d). By contrast, ALK6 MO was fully rescued by co-injection of alk6 plasmid DNA (Fig. 6c and d), which again confirmed a specific, non-redundant function of ALK6 in the neural crest. Injection of plasmid DNA typically results in a mosaic expression of the gene. Assuming that the ALK6 knock-down phenotype could be compensated partially by expansion of the residual neural crest progenitor population, the plasmid would restore ALK6 in a subset of cells and thereby increase this progenitor population sufficiently to allow full regeneration of the neural crest. Notably, maintenance of the neural crest fate during neurulation requires secreted growth factors that are derived from adjacent tissues including BMPs from the non-neural ectoderm and Wnt signals from the underlying paraxial mesoderm [14, 61, 90]. Therefore, ALK6 function could also be indirect via a secreted factor. In this case, restoring ALK6 function in a mosaic pattern by plasmid DNA injection would also be sufficient to fully rescue the phenotype because the secreted protein would act on all receiving cells within its range of action.

Altogether, these results demonstrate a role of ALK3 and ALK6 in the early specification of neural crest precursors whereas exclusively ALK6 is required for neural crest maintenance and migration in post-gastrula stages.

In this study, we have demonstrated that ALK3 and ALK6 are required for early neural crest precursor specification during gastrulation, although likely to be independent from each other. Consistent with a role of both receptors in early BMP-dependent dorso-ventral patterning of the embryo as shown and discussed above, it is conceivable that ALK3 and ALK6 signaling first contributes to positioning of the neural plate border and then mediates the moderate activation of BMP signaling in cells lateral of the neural plate that leads to the expression of neural plate border genes such as $m s x 2$. At late gastrula and early neurula stages, ALK3 is expressed in this region, and ALK6 expression is upregulated in the anterior neural plate and at the neural plate border from NF stage 12 onwards. This locally elevated expression correlates temporally and spatially with a local activation of Smad, and we have demonstrated that once again both type I receptors play a role in this process. However, we also observed that specifically ALK6, but not ALK3, plays an essential role in post-gastrula neural crest development.

The transition from cell fate specification at the neural plate border to maintenance of neural crest identity and further development takes place in early neurula stages. Based on expression patterns and functional analyses, we propose that a switch from an early, cooperative and redundant function of ALK3 and ALK6 in neural crest specification towards a highly specific function of ALK6 in neural crest maintenance and migration takes place during this phase. This could be related to a change in BMP ligands that are available. During early embryonic development, BMP2, BMP4 and BMP7 are expressed and required for dorso-ventral patterning, and all three ligands can signal via ALK3 or ALK6 or heteromeric receptor complexes [34, 64, 84]. A recent study in zebrafish showed that in early neurulation two distinct domains of active BMP signaling demarcate the borders between epidermis, pre-placodal ectoderm and the neural crest; it also showed that this local BMP activation depends on GDF6, also known as BMP13 [101]. In Xenopus, gdf6 is expressed in a single stripe at the neural plate border from late gastrula stage until late neurula stages [102], overlapping with ALK6 expression as shown in Fig. 1a. Consistently, we detected only one 
stripe of pSmad1/5/8 along the neural plate border at NF stage 13. Despite this difference, which might be due to temporal divergence of neural crest and placodal specification between zebrafish and Xenopus, it is likely that GDF6 mediated local activation of BMP signaling in the neural crest is conserved in both species. GDF6 signals via ALK3 and ALK6 but displays a preference towards ALK6 [42]. We have demonstrated herein that in Xenopus the transition from cell fate specification to maintenance of neural crest identity is accompanied by a shift in type I receptor requirement towards ALK6. Therefore we propose that post-gastrula neural crest development specifically requires ALK6 to mediate GDF6 signaling, a hypothesis that needs to be further investigated in the future.

\section{Conclusion}

Here we have demonstrated overlapping and nonredundant functions of the type I BMP receptors ALK3 and ALK6 in early Xenopus development. Both contribute to BMP dependent ventral identity, but ALK6 is additionally required for gene expression and size of the dorsal organizer in Xenopus embryos. These results show that despite overlapping expression patterns and activation of the same Smad signaling pathway, ALK3 and ALK6 exert temporally and spatially specific, diverging functions; indeed, they are important factors in the regulatory network that controls patterning of early embryos and the ectoderm.

In addition, we have demonstrated a highly specific expression of ALK6 in the neural crest and an exclusive requirement of ALK6 in neural crest induction and development. ALK6 likely acts a receptor for GDF6 in the neural crest and mediates neural crest development via an evolutionary conserved mechanism in the transition from neural crest specification to maintenance and further determination of cell fate.

\section{Methods}

Morpholinos, plasmids and antibodies

ALK3 and ALK6 Morpholinos (ALK3 MO 1: TTCTTG

AAGAAGTATGCTCGCCTTT; ALK3 MO 2: CAACCA ACCCATCCCTTGTGCCGGA; ALK6 MO 1: ACTCCA CTCTCTGTTCCTCCTTTGT; ALK6 MO 2: TTGGGA ACTTGTCAAACAACCGGCC) and a Control Morpholino (Control MO) were purchased from Gene Tools LLC, USA.

Full length coding sequences for Xenopus alk3, alk6, and $m s x 2$ were amplified from a stage 11-17 cDNA pool and cloned into the pCRII TA vector (ThermoFisher Scientific, USA). For cloning of the Flag-tagged full-length Xenopus ALK3 and ALK6 (ALK3-Flag and ALK6-Flag), the coding sequences of Xenopus alk3 and alk6 were subcloned into the EcoRI and XhoI sites of a pCS2+ vector [103] in frame with a Flag-tag. The 5' UTRs of alk3 and alk6 were similarly amplified and cloned into the pCS2+ vector $5^{\prime}$ of an egfp coding sequence. The full-length sequence of the alk6 mRNA has been submitted to Genebank (BankIt1812091 Хеnopus, KR052160). The in situ probes for chordin, sox2 and twist were kind gifts of E. DeRobertis and Doris Wedlich.

The following commercial antibodies were used: rabbit anti-GFP (Abcam, UK) and mouse anti-GAPDH (Proteintech Group, Inc., USA). Secondary antibodies were antimouse-Alkaline Phosphatase and anti-rabbit-Alkaline Phosphatase (Cell Signaling Technology, Inc. USA).

\section{Xenopus laevis embryos and microinjection}

Xenopus embryos were generated and cultured according to general protocols and staged according to the normal table of Nieuwkoop and Faber [55]. All procedures were performed according to the German animal use and care law (Tierschutzgesetz) and approved by the local authorities and committees (animal care and housing approval: I/39/EE006, Veterinäramt Erlangen; animal experiments approval: 54-2532.2-8/08, German state administration Bavaria/Regierung von Mittelfranken).

RNA for microinjection was prepared using the mMessage mMachine Kit (ThermoFisher Scientific, USA). The following amounts were injected: $500 \mathrm{pg}$ for alk3-5'-gfp and alk6-5'-gfp, $50 \mathrm{pg}$ of alk3-flag and alk6-flag RNA; 25 pg of pCS2 alk3-flag and pCS2 alk6-flag DNA and $100 \mathrm{pg}$ of pCS2- $\beta$-galactosidase DNA. Knock-down was achieved by injection of $0.8 \mathrm{pmol}$ or $1.6 \mathrm{pmol}$ of ALK3 $\mathrm{MO}$ and ALK6 MO as indicated.

Embryos were injected and cultured until they reached the desired stage as indicated.

For subsequent in situ hybridization, single side injections were performed and traced by co-injection of pCS2- $\beta$-galactosidase DNA. The injected side was visualized by $ß$-galactosidase staining and in situ hybridizations were carried out, as described by Harland [104], using chordin [77], sox2 [105], twist [106], msx2, alk3, alk6 or bmpr 2 as antisense probes, respectively.

\section{RT-PCR}

Total RNA was extracted from Xenopus embryos of the indicated developmental stages (High Pure RNA Isolation Kit, Roche, Germany), reverse transcribed using MMLV reverse transcriptase (New England Biolabs, USA) and the indicated transcripts were amplified from the resulting cDNA using OneTaq Polymerase (New England Biolabs, USA). Primer sequences are provided in Additional file 8: Table S1. For quantification of transcription levels of alk3 and alk6, real-time RT-PCR was carried out using Brilliant III Sybr Green Master Mix and the Agilent AriaMX Real Time PCR 
system (Agilent Technologies, USA). Transcription levels of alk3 and alk6 were calculated using synthetic alk3 and alk6 cDNA as external standard.

\section{Preparation of embryo lysates and western blotting}

Embryos were lysed in Lysis buffer (20 mM HEPES pH 7.9, $200 \mathrm{mM} \mathrm{KCl}, 0.5 \mathrm{mM}$ DTT, $0.5 \mathrm{mM}$ EDTA, $0.5 \% \mathrm{NP}-40,20 \%$ Glycerol) supplemented with complete Protease Inhibitor and PhosStop Phosphatase Inhibitor Cocktails (Roche, Germany) at $4{ }^{\circ} \mathrm{C}$. Lysates were cleared at $16,000 \times \mathrm{g}$ for $10 \mathrm{~min}$, and the protein concentration was determined using a BCA Assay, according to the manufacturer's instructions (Applichem, Germany). For Western blotting, proteins were separated in $10 \%$ polyacrylamid gels [107] and transferred to PVDF membranes; the desired proteins were then visualized by incubation with the appropriate antibodies and colorimetric detection using NBT/BCIP.

\section{Availability of supporting data}

Additional data supporting the methods and results of this article are included within the article and its additional files.

\section{Additional files}

\section{Additional file 1: Figure S1. Alignment of ALK6 and phylogenetic} analysis of ALK3 and ALK6 protein sequences. (PDF $174 \mathrm{~kb}$ )

Additional file 2: Figure S2. Temporal and spatial expression pattern of alk3 and alk6. (PDF $1708 \mathrm{~kb}$ )

Additional file 3: Figure S3. Expression of Activin receptors in dorso-ventrally bisected embryos. (PDF $131 \mathrm{~kb}$ )

Additional file 4: Figure S4. ALK3 MO and ALK6 MO specificity. (PDF $497 \mathrm{~kb}$ )

Additional file 5: Figure S5. ALK6 morphant embryos showed a lower survival rate. (PDF $116 \mathrm{~kb}$ )

Additional file 6: Figure S6. Knock-down of ALK3 in the dorsal ectoderm results in an expansion of neural tissue. (PDF $159 \mathrm{~kb}$ )

Additional file 7: Figure S7. Phenotypes of ALK3 and ALK6 morphant embryos are rescued with alk3 or alk6 RNA. (PDF $361 \mathrm{~kb}$ )

Additional file 8: Table S1. Primer sequences for RT-PCR and cloning (PDF $51 \mathrm{~kb}$ )

\section{Competing interests}

The authors declare that they have no competing interests.

\section{Authors' contributions}

CS analyzed expression patterns. CS and JH carried out knock-down and rescue experiments, documented and interpreted results. JH performed image analysis. AS conceived the study; participated in its design, coordination and data analysis; and wrote the manuscript. All authors have read and approved the final manuscript.

\section{Acknowledgements}

The authors thank Helena Pissarek for her help with injections and in situ hybridizations and E. De Robertis and D. Wedlich for providing plasmids.

Received: 7 July 2015 Accepted: 5 January 2016

Published online: 19 January 2016

\section{References}

1. Urist MR. Bone: formation by autoinduction. Science. 1965;150:893-9.

2. Wozney JM, Rosen V, Celeste AJ, Mitsock LM, Whitters MJ, Kriz RW, et al. Novel regulators of bone formation: molecular clones and activities. Science. 1988;242:1528-34

3. Luyten FP, Cunningham NS, Ma S, Muthukumaran N, Hammonds RG, Nevins WB, et al. Purification and partial amino acid sequence of osteogenin, a protein initiating bone differentiation. J Biol Chem. 1989;264:13377-80.

4. Ferguson EL, Anderson KV. Decapentaplegic acts as a morphogen to organize dorsal-ventral pattern in the Drosophila embryo. Cell. 1992;71:451-61.

5. Wharton KA, Ray RP, Gelbart WM. An activity gradient of decapentaplegic is necessary for the specification of dorsal pattern elements in the Drosophila embryo. Development. 1993;117:807-22.

6. Hawley SH, Wünnenberg-Stapleton K, Hashimoto C, Laurent MN, Watabe T, Blumberg BW, et al. Disruption of BMP signals in embryonic Xenopus ectoderm leads to direct neural induction. Genes Dev. 1995;9:2923-35.

7. Dale L, Howes G, Price BM, Smith JC. Bone morphogenetic protein 4: a ventralizing factor in early Xenopus development. Development. 1992:115:573-85.

8. Jones CM, Lyons KM, Lapan PM, Wright CV, Hogan BL. DVR-4 (bone morphogenetic protein-4) as a posterior-ventralizing factor in Xenopus mesoderm induction. Development. 1992;115:639-47.

9. Jones CM, Lyons KM, Hogan BL. Involvement of Bone Morphogenetic Protein-4 (BMP-4) and Vgr-1 in morphogenesis and neurogenesis in the mouse. Development. 1991;111:531-42.

10. Kozmikova I, Candiani S, Fabian P, Gurska D, Kozmik Z. Essential role of Bmp signaling and its positive feedback loop in the early cell fate evolution of chordates. Dev Biol. 2013;382:538-54.

11. Liu A, Niswander LA. Bone morphogenetic protein signalling and vertebrate nervous system development. Nat Rev Neurosci. 2005;6:945-54.

12. Chalazonitis A, Kessler JA. Pleiotropic effects of the bone morphogenetic proteins on development of the enteric nervous system. Dev Neurobiol. 2012;72:843-56.

13. Tribulo C. Regulation of Msx genes by a Bmp gradient is essential for neural crest specification. Development. 2003;130:6441-52.

14. Steventon B, Araya C, Linker C, Kuriyama S, Mayor R. Differential requirements of BMP and Wnt signalling during gastrulation and neurulation define two steps in neural crest induction. Development. 2009;136:771-9.

15. Schlosser G. Induction and specification of cranial placodes. Dev Biol. 2006;294:303-51.

16. Furuta $Y$, Hogan BL. BMP4 is essential for lens induction in the mouse embryo. Genes Dev. 1998;12:3764-75.

17. Li H, Corrales CE, Wang Z, Zhao Y, Wang Y, Liu H, et al. BMP4 signaling is involved in the generation of inner ear sensory epithelia. BMC Dev Biol. 2005:5:16.

18. Pujades C, Kamaid A, Alsina B, Giraldez F. BMP-signaling regulates the generation of hair-cells. Dev Biol. 2006;292:55-67.

19. Dudley AT, Lyons KM, Robertson EJ. A requirement for bone morphogenetic protein-7 during development of the mammalian kidney and eye. Genes Dev. 1995;9:2795-807.

20. Murali D, Yoshikawa S, Corrigan RR, Plas DJ, Crair MC, Oliver G, et al. Distinct developmental programs require different levels of Bmp signaling during mouse retinal development. Development. 2005;132:913-23.

21. Shi $Y$, Katsev $S$, Cai C, Evans S. BMP signaling is required for heart formation in vertebrates. Dev Biol. 2000;224:226-37.

22. Simic $\mathrm{P}$, Vukicevic S. Bone morphogenetic proteins in development and homeostasis of kidney. Cytokine Growth Factor Rev. 2005;16:299-308.

23. Gordon J, Patel SR, Mishina Y, Manley NR. Evidence for an early role for BMP4 signaling in thymus and parathyroid morphogenesis. Dev Biol. 2010;339:141-54.

24. Neumann JC, Chandler GL, Damoulis VA, Fustino NJ, Lillard K, Looijenga L, et al. Mutation in the type IB bone morphogenetic protein receptor Alk6b impairs germ-cell differentiation and causes germ-cell tumors in zebrafish. Proc Natl Acad Sci U S A. 2011;108:13153-8.

25. Snyder A, Fraser ST, Baron MH. Bone morphogenetic proteins in vertebrate hematopoietic development. J Cell Biochem. 2004;93:224-32.

26. Hogan BL. Bone morphogenetic proteins in development. Curr Opin Genet Dev. 1996;6:432-8.

27. Hogan BL. Bone morphogenetic proteins: multifunctional regulators of vertebrate development. Genes Dev. 1996;10:1580-94. 
28. Niswander L. Interplay between the molecular signals that control vertebrate limb development. Int J Dev Biol. 2002;46:877-81.

29. Wu MY, Hill CS. Tgf-beta superfamily signaling in embryonic development and homeostasis. Dev Cell. 2009;16:329-43.

30. Kawabata M, Chytil A, Moses HL. Cloning of a novel type II serine/threonine kinase receptor through interaction with the type I transforming growth factor-beta receptor. J Biol Chem. 1995;270:5625-30.

31. Rosenzweig BL, Imamura T, Okadome T, Cox GN, Yamashita H, Ten Dijke P, et al. Cloning and characterization of a human type II receptor for bone morphogenetic proteins. Proc Natl Acad Sci U S A. 1995;92:7632-6.

32. Yamashita H, Ten Dijke P, Huylebroeck D, Sampath TK, Andries M, Smith JC, et al. Osteogenic protein-1 binds to activin type $\|$ receptors and induces certain activin-like effects. J Cell Biol. 1995;130:217-26.

33. Macías-Silva M, Hoodless PA, Tang SJ, Buchwald M, Wrana JL. Specific activation of Smad1 signaling pathways by the BMP7 type I receptor, ALK2. J Biol Chem. 1998;273:25628-36.

34. Koenig BB, Cook JS, Wolsing DH, Ting J, Tiesman JP, Correa PE, et al. Characterization and cloning of a receptor for BMP-2 and BMP-4 from NIH 3 T3 cells. Mol Cell Biol. 1994;14:5961-74.

35. Ten Dijke P, Ichijo H, Franzén P, Schulz P, Saras J, Toyoshima H, et al. Activin receptor-like kinases: a novel subclass of cell-surface receptors with predicted serine/threonine kinase activity. Oncogene. 1993;8:2879-87.

36. Liu F, Ventura F, Doody J, Massagué J. Human type II receptor for bone morphogenic proteins (BMPs): extension of the two-kinase receptor model to the BMPs. Mol Cell Biol. 1995;15:3479-86.

37. Mathews LS, Vale WW. Expression cloning of an activin receptor, a predicted transmembrane serine kinase. Cell. 1991;65:973-82.

38. Mathews LS, Vale WW, Kintner CR. Cloning of a second type of activin receptor and functional characterization in Xenopus embryos. Science. 1992:255:1702-5

39. Attisano L, Wrana JL, Cheifetz S, Massagué J. Novel activin receptors: distinct genes and alternative mRNA splicing generate a repertoire of serine/ threonine kinase receptors. Cell. 1992;68:97-108.

40. Massagué J, Attisano L, Wrana JL. The TGF-beta family and its composite receptors. Trends Cell Biol. 1994;4:172-8.

41. Chang H, Brown CW, Matzuk MM. Genetic analysis of the mammalian transforming growth factor-beta superfamily. Endocr Rev. 2002;23:787-823.

42. Mazerbourg S, Sangkuhl K, Luo C-W, Sudo S, Klein C, Hsueh AJW. Identification of receptors and signaling pathways for orphan bone morphogenetic protein/growth differentiation factor ligands based on genomic analyses. J Biol Chem. 2005;280:32122-32

43. Shi $Y$, Massagué J. Mechanisms of TGF-beta signaling from cell membrane to the nucleus. Cell. 2003;113:685-700.

44. Massagué J, Wotton D. Transcriptional control by the TGF-beta/Smad signaling system. EMBO J. 2000;19:1745-54.

45. Fainsod A, Steinbeisser $H$, De Robertis EM. On the function of BMP-4 in patterning the marginal zone of the Xenopus embryo. EMBO J. 1994;13:5015-25.

46. De Robertis EM, Kuroda H. Dorsal-ventral patterning and neural induction in Xenopus embryos. Annu Rev Cell Dev Biol. 2004;20:285-308.

47. Ramel M-C, Hill CS. The ventral to dorsal BMP activity gradient in the early zebrafish embryo is determined by graded expression of BMP ligands. Dev Biol. 2013;378:170-82.

48. Clement JH, Fettes P, Knöchel S, Lef J, Knöchel W. Bone morphogenetic protein 2 in the early development of Xenopus laevis. Mech Dev. 1995;52:357-70

49. Moos M, Wang S, Krinks M. Anti-dorsalizing morphogenetic protein is a novel TGF-beta homolog expressed in the Spemann organizer. Development. 1995;121:4293-301.

50. Reversade B, Kuroda H, Lee H, Mays A, De Robertis EM. Depletion of Bmp2, Bmp4, Bmp7 and Spemann organizer signals induces massive brain formation in Xenopus embryos. Development. 2005;132:3381-92

51. Reversade B, De Robertis EM. Regulation of ADMP and BMP2/4/7 at opposite embryonic poles generates a self-regulating morphogenetic field. Cell. 2005;123:1147-60

52. Hocking JC, McFarlane S. Expression of Bmp ligands and receptors in the developing Xenopus retina. Int J Dev Biol. 2007;51:161-5.

53. Rankin SA, Thi Tran H, Wlizla M, Mancini P, Shifley ET, Bloor SD, et al. A Molecular atlas of Xenopus respiratory system development. Dev Dyn. 2014;244:69-85.
54. Park EC, Hayata T, Cho KWY, Han J-K. Xenopus cDNA microarray identification of genes with endodermal organ expression. Dev Dyn. 2007;236:1633-49.

55. Niewkoop PD, Faber J. eds. Normal table of Xenopus laevis (Daudin). Garland Publishing Inc., New York; 1994. ISBN 9780815318965.

56. Nikaido M, Tada M, Ueno N. Restricted expression of the receptor serine/ threonine kinase BMPR-IB in zebrafish. Mech Dev. 1999;82:219-22.

57. Dewulf N, Verschueren K, Lonnoy O, Morén A, Grimsby S, Vande Spiegle K, et al. Distinct spatial and temporal expression patterns of two type I receptors for bone morphogenetic proteins during mouse embryogenesis. Endocrinology. 1995;136:2652-63.

58. Steventon B, Carmona-Fontaine C, Mayor R. Genetic network during neural crest induction: from cell specification to cell survival. Semin Cell Dev Biol. 2005; 16:647-54.

59. Sauka-Spengler T, Bronner-Fraser M. A gene regulatory network orchestrates neural crest formation. Nat Rev Mol Cell Biol. 2008;9:557-68.

60. Brugger SM, Merrill AE, Torres-Vazquez J, Wu N, Ting M-C, Cho JY-M, et al. A phylogenetically conserved cis-regulatory module in the Msx2 promoter is sufficient for BMP-dependent transcription in murine and Drosophila embryos. Development. 2004;131:5153-65.

61. Sakai D, Tanaka Y, Endo Y, Osumi N, Okamoto H, Wakamatsu Y. Regulation of Slug transcription in embryonic ectoderm by beta-catenin-Lef/Tcf and BMP-Smad signaling. Dev Growth Differ. 2005;47:471-82.

62. Frisch A, Wright CV. XBMPRII, a novel Xenopus type II receptor mediating BMP signaling in embryonic tissues. Development. 1998;125:431-42.

63. Schohl A, Fagotto F. Beta-catenin. MAPK and Smad signaling during early Xenopus development. 2002;129:37-52.

64. Yamaji N, Celeste AJ, Thies RS, Song JJ, Bernier SM, Goltzman D, et al. A mammalian serine/threonine kinase receptor specifically binds BMP-2 and BMP-4. Biochem Biophys Res Commun. 1994;205:1944-51.

65. Mishina Y, Suzuki A, Ueno N, Behringer RR. Bmpr encodes a type I bone morphogenetic protein receptor that is essential for gastrulation during mouse embryogenesis. Genes Dev. 1995;9:3027-37.

66. Yi SE, Daluiski A, Pederson R, Rosen V, Lyons KM. The type I BMP receptor BMPRIB is required for chondrogenesis in the mouse limb. Development. 2000;127:621-30.

67. Rajagopal R, Huang J, Dattilo LK, Kaartinen V, Mishina Y, Deng C-X, et al. The type I BMP receptors, Bmpr1a and Acvr1, activate multiple signaling pathways to regulate lens formation. Dev Biol. 2009;335:305-16.

68. Lim Y, Cho G, Minarcik J, Golden J. Altered BMP signaling disrupts chick diencephalic development. Mech Dev. 2005;122:603-20.

69. Liu J, Wilson S, Reh T. BMP receptor $1 \mathrm{~b}$ is required for axon guidance and cell survival in the developing retina. Dev Biol. 2003;256:34-48.

70. Caronia G, Wilcoxon J, Feldman P, Grove EA. Bone morphogenetic protein signaling in the developing telencephalon controls formation of the hippocampal dentate gyrus and modifies fear-related behavior. J Neurosci. 2010;30:6291-301.

71. Thomas AJ, Erickson CA. The making of a melanocyte: the specification of melanoblasts from the neural crest. Pigment Cell Melanoma Res. 2008;21:598-610.

72. Connors SA, Trout J, Ekker M, Mullins MC. The role of tolloid/mini fin in dorsoventral pattern formation of the zebrafish embryo. Development. 1999;126:3119-30

73. Mullins MC, Hammerschmidt M, Kane DA, Odenthal J, Brand M, van Eeden FJ, et al. Genes establishing dorsoventral pattern formation in the zebrafish embryo: the ventral specifying genes. Development. 1996;123:81-93.

74. Tucker AS, Slack JMW. Independent induction and formation of the dorsal and ventral fins in Xenopus laevis. Dev Dyn. 2004;230:461-7.

75. Mintzer KA, Lee MA, Runke G, Trout J, Whitman M, Mullins MC. Lost-a-fin encodes a type I BMP receptor, Alk8, acting maternally and zygotically in dorsoventral pattern formation. Development. 2001;128:859-69.

76. Bauer H, Lele Z, Rauch GJ, Geisler R, Hammerschmidt M. The type I serine/ threonine kinase receptor Alk8/Lost-a-fin is required for Bmp2b/7 signal transduction during dorsoventral patterning of the zebrafish embryo. Development. 2001;128:849-58.

77. Sasai Y, Lu B, Steinbeisser H, Geissert D, Gont LK, De Robertis EM. Xenopus chordin: a novel dorsalizing factor activated by organizer-specific homeobox genes. Cell. 1994;79:779-90.

78. Cho KW, Blumberg B, Steinbeisser H, De Robertis EM. Molecular nature of Spemann's organizer: the role of the Xenopus homeobox gene goosecoid. Cell. 1991;67:1111-20. 
79. Gawantka V, Delius H, Hirschfeld K, Blumenstock C, Niehrs C. Antagonizing the Spemann organizer: role of the homeobox gene Xvent-1. EMBO J. 1995; 14:6268-79

80. Salic AN, Kroll KL, Evans LM, Kirschner MW. Sizzled: a secreted Xwnt8 antagonist expressed in the ventral marginal zone of Xenopus embryos. Development. 1997:124:4739-48.

81. Graff JM, Thies RS, Song JJ, Celeste AJ, Melton DA. Studies with a Xenopus BMP receptor suggest that ventral mesoderm-inducing signals override dorsal signals in vivo. Cell. 1994;79:169-79.

82. Suzuki A, Thies RS, Yamaji N, Song JJ, Wozney JM, Murakami K, et al. A truncated bone morphogenetic protein receptor affects dorsal-ventral patterning in the early Xenopus embryo. Proc Natl Acad Sci U S A. 1994;91:10255-9.

83. Nohno T, Ishikawa T, Saito T, Hosokawa K, Noji S, Wolsing DH, et al. Identification of a human type $\|$ receptor for bone morphogenetic protein-4 that forms differential heteromeric complexes with bone morphogenetic protein type I receptors. J Biol Chem. 1995;270:22522-6.

84. Little SC, Mullins MC. Bone morphogenetic protein heterodimers assemble heteromeric type I receptor complexes to pattern the dorsoventral axis. Nat Cell Biol. 2009;11:637-43.

85. Yoon BS, Ovchinnikov DA, Yoshii I, Mishina Y, Behringer RR, Lyons KM. Bmprla and Bmpr1b have overlapping functions and are essential for chondrogenesis in vivo. Proc Natl Acad Sci U S A. 2005;102:5062-7.

86. Marchant L, Linker C, Ruiz P, Guerrero N, Mayor R. The inductive properties of mesoderm suggest that the neural crest cells are specified by a BMP gradient. Dev Biol. 1998;198:319-29.

87. Betancur P, Bronner-Fraser M, Sauka-Spengler T. Assembling neural crest regulatory circuits into a gene regulatory network. Annu Rev Cell Dev Biol. 2010;26:581-603.

88. Wawersik S, Evola C, Whitman M. Conditional BMP inhibition in Xenopus reveals stage-specific roles for BMPs in neural and neural crest induction. Dev Biol. 2005;277:425-42.

89. Suzuki A, Ueno N, Hemmati-Brivanlou A. Xenopus msx1 mediates epiderma induction and neural inhibition by BMP4. Development. 1997;124:3037-44.

90. Steventon B, Mayor R. Early neural crest induction requires an initial inhibition of Wnt signals. Dev Biol. 2012;365:196-207.

91. Li B, Kuriyama S, Moreno M, Mayor R. The posteriorizing gene Gbx2 is a direct target of Wnt signalling and the earliest factor in neural crest induction. Development. 2009;136:3267-78.

92. Bang AG, Papalopulu N, Goulding MD, Kintner C. Expression of Pax-3 in the lateral neural plate is dependent on a Wnt-mediated signal from posterior nonaxial mesoderm. Dev Biol. 1999;212:366-80.

93. Nakata K, Nagai T, Aruga J, Mikoshiba K. Xenopus Zic family and its role in neural and neural crest development. Mech Dev. 1998;75:43-51.

94. Monsoro-Burq A-H, Wang E, Harland R. Msx1 and Pax3 cooperate to mediate FGF8 and WNT signals during Xenopus neural crest induction. Dev Cell. 2005;8:167-78.

95. Plouhinec J-L, Roche DD, Pegoraro C, Figueiredo AL, Maczkowiak F, Brunet $\sqcup$, et al. Pax3 and Zic1 trigger the early neural crest gene regulatory network by the direct activation of multiple key neural crest specifiers. Dev Biol. 2014;386:461-72.

96. Khadka D, Luo T, Sargent TD. Msx1 and Msx2 have shared essential functions in neural crest but may be dispensable in epidermis and axis formation in Xenopus. Int J Dev Biol. 2006;50:499-502.

97. O'Donnell M, Hong C-S, Huang X, Delnicki RJ, Saint-Jeannet J-P. Functional analysis of Sox8 during neural crest development in Xenopus. Development. 2006;133:3817-26.

98. Sato T, Sasai N, Sasai Y. Neural crest determination by co-activation of Pax3 and Zic1 genes in Xenopus ectoderm. Development. 2005;132:2355-63.

99. Nikitina N, Sauka-Spengler T, Bronner-Fraser M. Dissecting early regulatory relationships in the lamprey neural crest gene network. Proc Natl Acad Sci U S A. 2008;105:20083-8.

100. Couly G, Grapin-Botton A, Coltey P, Le Douarin NM. The regeneration of the cephalic neural crest, a problem revisited: the regenerating cells originate from the contralateral or from the anterior and posterior neural fold. Development. 1996;122:3393-407.

101. Reichert S, Randall RA, Hill CS. A BMP regulatory network controls ectodermal cell fate decisions at the neural plate border. Development. 2013;140:4435-44.

102. Chang C, Hemmati-Brivanlou A. Xenopus GDF6, a new antagonist of noggin and a partner of BMPs. Development. 1999:126:3347-57.
103. Rupp RA, Snider L, Weintraub $H$. Xenopus embryos regulate the nuclear localization of XMyoD. Genes Dev. 1994;8:1311-23.

104. Harland RM. In situ hybridization: an improved whole-mount method for Xenopus embryos. Methods Cell Biol. 1991;36:685-95.

105. Mizuseki K, Kishi M, Matsui M, Nakanishi S, Sasai Y. Xenopus Zic-related-1 and Sox-2, two factors induced by chordin, have distinct activities in the initiation of neural induction. Development. 1998;125:579-87.

106. Hopwood ND, Pluck A, Gurdon JB. A Xenopus mRNA related to Drosophila twist is expressed in response to induction in the mesoderm and the neural crest. Cell. 1989;59:893-903.

107. Laemmli UK. Cleavage of structural proteins during the assembly of the head of bacteriophage T4. Nature. 1970;227:680-5.

\section{Submit your next manuscript to BioMed Central and we will help you at every step:}

- We accept pre-submission inquiries

- Our selector tool helps you to find the most relevant journal

- We provide round the clock customer support

- Convenient online submission

- Thorough peer review

- Inclusion in PubMed and all major indexing services

- Maximum visibility for your research

Submit your manuscript at www.biomedcentral.com/submit
C Biomed Central 